\title{
Impacto hormonal e inflamatório de diferentes composições dietéticas: ênfase em padrões alimentares e fatores dietéticos específicos
}

\author{
Hormonal and inflammatory impact of different dietetic composition: \\ emphasis on dietary patterns and specific dietary factors
}

Josefina Bressan', Helen H. M. Hermsdorff',

María Ángeles Zulet ${ }^{2}$, José Alfredo Martínez ${ }^{2}$

\begin{abstract}
RESUMO
A adoção de um padrão alimentar saudável, caracterizado pelo consumo de frutas, hortaliças, carnes magras, lácteos desnatados, frutos secos e moderada ingestão de óleos vegetais e álcool, é um fator determinante para um menor risco de doenças crônicas como a obesidade, a síndrome metabólica e as doenças cardiovasculares. Esse efeito benéfico pode ser explicado, pelo menos em parte, por seu papel modulador sobre biomarcadores da sensibilidade insulínica, da aterogênese, bem como os de inflamação e de função endotelial. Por outra parte, a ingestão de componentes específicos da dieta como os ácidos graxos insaturados (oleico e alfa-linolênico) e os micronutrientes com propriedades antioxidantes (vitaminas $A$, E e C; selênio e zinco) vêm sendo discutida, em razão de sua potencial ação protetora perante a ocorrência das doenças crônicas e possíveis benefícios na regulação hormonal, metabólica e inflamatória que esses fatores dietéticos podem proporcionar dentro de um tratamento nutricional para a obesidade e a síndrome metabólica. Arq Bras Endocrinol Metab. 2009;53(5):572-81.
\end{abstract}

1 Departamento de Nutrição e Saúde, Universidade Federal de Viçosa (UFV) - Viçosa, MG, Brasil ${ }^{2}$ Departamento de Ciencias de la Alimentación, Fisiología y Toxicología, Universidad de Navarra, España
Correspondência para: Josefina Bressan

Departamento de Nutrição e Saúde, Universidade Federal de Viçosa - Campus Universitário 35751-000 - Viçosa, MG, Brasil jbrm@ufv.br

Recebido em 9/Abr/2009 Aceito em 2/Jun/2009
Descritores

Hábitos alimentares; ácidos graxos; micronutrientes; hormônios; inflamação; síndrome metabólica

\begin{abstract}
Healthy dietary pattern, characterized by the consumption of fruits, vegetables, white meats, skim dairy products, nuts and moderate intake of vegetable oils and alcohol, is an important factor for a lower risk of chronic disease such as obesity, metabolic syndrome and cardiovascular disease. This beneficial effect can be explained, at least partially, by its modulating role on biomarkers of insulin sensitivity and atherosclerosis as well as of inflammation and endothelial function. On the other hand, the intake of specific dietary factors, such as unsaturated fatty acids (oleic and alpha-linolenic) and micronutrients with antioxidant properties (vitamins A, E and C; selenium, zinc) has been discussed, due to its potential protector action due to chronic disease occurrence and its possible profits in hormonal, metabolic and inflammatory regulations that these dietetic factors can provide within a nutritional treatment to obesity and metabolic syndrome. Arq Bras Endocrinol Metab. 2009;53(5):572-81.

Keywords

Food habits; fatty acids; micronutrients; hormones; inflammation; metabolic syndrome
\end{abstract}

\section{INTRODUÇÃO}

$\mathrm{N}$ os dias atuais, a obesidade está, reconhecidamente, associada à prevalência de diabetes melito tipo 2 (DMT2) e a um maior risco para as doenças cardiovas- culares (DCV) (1). Essa associação deve-se, em grande parte, à capacidade do tecido adiposo de secretar adipocinas com propriedades inflamatórias. Entre elas, destacam-se a leptina, o fator de necrose tumoral-alfa 
(TNF- $\alpha$ ), a interleucina-6 (IL6), o inibidor de plasminogênio ativado-1 (PAI-1), a resistina, a adiponectina e a proteína transportadora de retinol-4 (RBP4) $(2,3)$. Essas adipocinas estão relacionadas, direta ou indiretamente, a processos inflamatórios e metabólicos que contribuem para a incidência da aterosclerose, dislipidemias, hipertensão arterial, resistência insulínica (RI) e DMT2, representando um relevante nexo entre a adiposidade e complicações associadas (3-5).

Além da modificação das concentrações plasmáticas das adipocinas, o processo inflamatório crônico subclínico associado à obesidade e à síndrome metabólica (SM) também induz a um aumento nas concentrações de marcadores inflamatórios derivados dos hepatócitos como a proteína C reativa (PCR), a proteína amiloide sérica A (SSA) e o fibrinogênio, bem como de marcadores da função endotelial, como as seletinas e as moléculas de adesão, todos relevantes no aumento do risco para DCV $(2,6,7)$.

Por outro lado, a ingestão calórica e a distribuição dos macronutrientes em uma alimentação habitual têm um papel fundamental no balanço energético e no controle do peso corporal $(8,9)$. Neste contexto, diversos estudos mostram a relação entre os padrões alimentares de distintas populações e os marcadores inflamatórios relacionados à SM (10-14). Da mesma forma, fatores dietéticos específicos vêm sendo investigados, destacando-se o perfil de ácidos graxos (15-17) e os micronutrientes com propriedades antioxidantes (18-20).

Assim, essa revisão tem como objetivo discutir o efeito modulador de padrões alimentares, bem como de fatores dietéticos específicos como os ácidos graxos e os micronutrientes com propriedades antioxidantes sobre a regulação hormonal e sobre o estado inflamatório crônico subclínico.

\section{EFEITO DE PADRÕES ALIMENTARES SOBRE BIOMARCADORES INFLAMATÓRIOS}

Vários estudos epidemiológicos vêm utilizando os padrões alimentares para avaliar o risco para doenças crônicas e a variação de biomarcadores relacionados à exposição à dieta como um todo $(10-12,21,22)$. Isso se deve à premissa de que a avaliação do efeito dos nutrientes isoladamente não é equivalente a do consumo do alimento com vários nutrientes, ou ainda, a de alimentos consumidos dentro de um padrão alimentar habitual, contendo vários alimentos (23). Assim, a análise de um padrão alimentar poderia facilitar a medição do efeito sinérgico do consumo habitual de alimentos e de nutrientes (Tabela 1). Para tanto, diversos índices ou escores vêm sendo desenhados, baseando-se nas recomendações dietéticas e nutricionais estabelecidas para a população estudada; no efeito em potencial do padrão alimentar sobre uma determinada enfermidade; em determinados grupos de análises, capazes de oferecer nutrientes específicos como grupo de alimentos ricos em antioxidantes ou ricos em gordura saturada (24).

Neste sentido, o índice de alimentação saudável (Healthy Eating Index, HEI) foi desenvolvido pelo Departamento de Agricultura dos Estados Unidos para avaliar a qualidade da dieta com relação às recomendações dietéticas e nutricionais para os norte-americanos (25). Outro padrão alimentar utilizado é o escore de alimentos recomendados (Recommended Food Score, RFS), que tem como base o consumo ( $\geq 1$ vez por semana) de alimentos recomendados em guias alimentares (26). Da mesma forma, o índice de qualidade da dieta (Diet Quality Index, DQI) (27) mede o consumo de oito grupos de alimentos e de nutrientes, com base nas recomendações do Committee on Diet and Health of the National Council Food and Nutrition Board, sendo, posteriormente, revisado (DQI-R) (11) de acordo com recomendações mais atuais. Por sua vez, o índice alternativo de alimentação saudável (Alternative Healthy eating Index, AHEI) foi desenhado a partir do HEI, mas com o objetivo de eleger a priori fontes de alimentos que capturam um padrão alimentar associado à redução do risco para doenças crônicas como as DCV e o câncer (28). O padrão alimentar saudável global (Comprehensive Healthy Dietary Pattern, CHDP) também foi desenvolvido para a avaliação do risco para aterosclerose e DCV em relação ao nível de exposição à dieta na coorte Multi-Ethnic Study of Atherosclerosis (MESA), sendo 47 grupos de alimentos segmentados em positivos (efeito de proteção), negativos ou neutros para DCV e marcadores da ocorrência de aterosclerose (21).

Padrões alimentares geograficamente característicos também vêm sendo muito investigados: 1) o padrão alimentar ocidental: alto consumo de carnes vermelhas, grãos refinados, leite e derivados integrais, fast food, gordura saturada e açúcares (29); 2 ) o padrão alimentar mediterrâneo: alto consumo de azeite de oliva, frutas, hortaliças, leguminosas, frutos secos e cereais integrais e moderado a alto consumo de peixe (dependendo da proximidade com a costa litorânea), bem como um consumo reduzido de carnes, de leite e derivados e de vinho (geralmente nas refeições principais) (13). Para 


\begin{tabular}{|c|c|}
\hline Índice (ref.) & Cálculo do índice \\
\hline HEI (25) & $\begin{array}{l}\text { Escore de 0-10 pontos, baseado no consumo de cada grupo de alimentos: cereais (pão, cereais, arroz, massas), hortaliças, frutas, produtos } \\
\text { lácteos (inclui iogurtes e queijos), carnes (carnes, aves, peixe, ovos, frutos secos, feijões secos), lipídio total, gordura saturada, colesterol, sódio, } \\
\text { variedade }\end{array}$ \\
\hline AHEI (28) & $\begin{array}{l}\text { Escore de } 0 \text { a } 10 \text { pontos baseado no consumo de cada grupo de alimentos: fibra de cereais, hortaliças, frutas, frutos secos e soja, razão entre } \\
\text { carnes branca e vermelha, gordura trans, AGPI:AGS, álcool. Uso de suplementos vitamínicos, com um escore de } 0 \text { a 7,5, de acordo com o tempo } \\
\text { de uso }\end{array}$ \\
\hline DQI (27) & $\begin{array}{l}\text { Escore de } 0 \text { a } 10 \text { pontos, baseado no consumo de } 8 \text { grupos de alimentos: cereais e leguminosas, hortaliças e frutas, proteínas, sódio, cálcio, } \\
\text { gordura total, gordura saturada e colesterol }\end{array}$ \\
\hline DQIR (11) & $\begin{array}{l}13 \text { componentes divididos em } 3 \text { grupos: } \\
\text { - Variedade: consumo de todos os grupos de alimentos } \\
\text { - Adequação: cereais, hortaliças, frutas, gordura total e saturada, colesterol, cálcio, ferro } \\
\text { - Moderação: açúcar total, gordura desproporcional, sódio, álcool }\end{array}$ \\
\hline RFS (26) & $\begin{array}{l}1 \text { ponto (por cada) se itens de alimentos forem consumidos pelo menos uma vez por semana: } \\
\text { Hortaliças ( } 26 \text { itens), frutas ( } 18 \text { itens), alimentos proteicos ( } 6 \text { itens), cereais ( } 5 \text { itens), produtos lácteos ( } 1 \text { item) }\end{array}$ \\
\hline CHDP (21) & $\begin{array}{l}47 \text { grupos de alimentos, segmentados em } 21 \text { grupos positivos }(+1), 15 \text { negativos }(-1) \text { ou } 11 \text { nêutros ( } 0 \text { ponto) diante da proteção para } \\
\text { aterosclerose. Total escore: grupo }(+, 0,-) \text { multiplicado pelo fator }(0,1,2,3) \text { de acordo com a quantidade ingerida } \\
\text { (+): hortaliças, frutas, frutos secos, carnes brancas, leite e derivados desnatados, soja, chá verde e preto, café e álcool } \\
\text { (-): carnes vermelhas e processadas, leite e derivados integrais, açúcares, óleos e gorduras acrescentados, batatas fritas, pizza, salgadinhos, café } \\
\text { cremado e sorvete com leite }\end{array}$ \\
\hline MDS (14) & $\begin{array}{l}8 \text { itens com escore de } 0 \text { a } 1 \text { ponto, de acordo com a frequência de consumo: hortaliças }(+) \text {, leguminosas }(+) \text {, frutas e frutos secos }(+) \text {, cereais }(+) \text {, } \\
\text { AGMl:AGS }(+) \text {, moderado consumo de álcool }(+) \text {, produtos lácteos }(-) \text {, carnes e derivados }(-)\end{array}$ \\
\hline MMDS (13) & $\begin{array}{l}9 \text { itens com escore de } 0 \text { a } 1 \text { ponto, de acordo com a frequência de consumo: hortaliças }(+) \text {, leguminosas }(+) \text {, frutas e frutos secos }(+) \text {, cereais }(+) \text {, } \\
\text { AGMI:AGS }(+) \text {, moderado consumo de álcool }(+) \text {, peixe }(+) \text {, produtos lácteos }(-) \text {, carnes e derivados }(-)\end{array}$ \\
\hline
\end{tabular}

HEl: healthy eating pattern; AHEl: alternate healthy eating pattern; DQI: diet quality index; DQI-R: diet quality index revised; CHDP: comprehensive healthy dietary pattern; RFS: recommended food score; MDS: Mediterranean diet score; MMDS: modified Mediterranean diet score. AGMI: ácido graxo monoinsaturado; AGPI: ácido graxo poli-insaturado; AGS: ácido graxo saturado.

estes últimos, os índices mais comuns são os desenhados para avaliar a dieta na população grega [Mediterranean Diet Score, MDS e Modified Mediterranean Diet Score, MMDS] $(13,14)$ e o índice alternativo para dieta Mediterrânea (alternate Mediterranean Diet Index, aMED), adaptado a partir do primeiro para ser usado com um questionário de frequência de consumo alimentar validado para a população norte-americana (10).

Em relação ao efeito da adoção dos padrões alimentares sobre as doenças crônicas, uma maior aderência ao HEI esteve associada a uma redução de $14 \%$ no risco para DCV em mulheres norte-americanas (12). Entretanto, AHEI foi capaz de predizer melhor o risco para DCV do que HEI e RFS, de modo que um maior valor para esse índice foi um fator de proteção para DCV em homens e mulheres (28). Por sua vez, um maior escore para CHDP foi negativamente associado a adiposidade, insulinemia, trigliceridemia e a alguns marcadores subclínicos de aterosclerose (21). Com relação à dieta mediterrânea, uma maior aderência a esse padrão alimentar (avaliada pelo índice MMDS) tem sido fator de proteção para a incidência de DMT2 e SM, bem como para mortalidade por $\operatorname{DCV}(22,30,31)$.
Dado que os padrões alimentares têm um papel determinante no risco para doenças crônicas e que a inflamação crônica subclínica está associada a uma maior ocorrência de SM e maior risco para DCV $(2-4,6,7)$, poder-se-ia propor que a adoção de padrões alimentares saudáveis influencia nos valores das concentrações de biomarcadores inflamatórios, como um mecanismo para a melhora das manifestações clínicas da SM e redução da mortalidade.

Neste sentido, em estudo transversal com mulheres com sobrepeso ou obesidade, no qual se avaliou a associação do padrão alimentar com marcadores de inflamação e função imune, uma maior qualidade na dieta (avaliada pelo índice DQI) foi associada a menores concentrações de PCR e SAA, bem como com uma menor proporção de linfócitos $\mathrm{T}$ helper, responsáveis pela ativação de macrófagos. Entretanto, a associação com os marcadores inflamatórios foi atenuada quando ajustada para a adiposidade (32). Também, participantes sem DMT2 e DCV da coorte MESA que tiveram maiores escores para o índice CHDP apresentaram menores níveis plasmáticos de PCR, IL6, homocisteína e fibrinogênio (21). Outro estudo transversal, em uma 
amostra japonesa, encontrou que uma aderência maior a um padrão alimentar saudável, caracterizado por um alto consumo de frutas e hortaliças, produtos de soja e peixe, foi inversamente associado às concentrações plasmáticas de PCR (33). Um padrão alimentar saudável, definido por um alto consumo de frutas, hortaliças, tomate, aves, leguminosas, chá, sucos de frutas e grãos integrais, foi inversamente associado a menores concentrações de PCR, sVCAM-1 e seletina-E, permanecendo a associação significativa para os dois primeiros, depois que o modelo foi ajustado pelo índice de massa corporal (IMC) e pela circunferência da cintura. Ao mesmo tempo, indivíduos que seguiam um padrão alimentar ocidental (rico em grãos refinados, carnes vermelhas e processadas, manteiga, lácteos integrais, doces, pizza, ovos, gorduras hidrogenadas e refrigerantes) tiveram maiores valores para SAA e IL6, independentemente de fatores de confusão (29).

Na coorte Nurses' Health Study, as mulheres, em sua maioria com sobrepeso, que tinham uma maior aderência ao índice AHEI, apresentaram concentrações de adiponectina $24 \%$ maiores e concentrações de resistina, PCR e de seletina-E, 16\%, 41\% e 19\% menores, respectivamente. Além disso, o escore de AHEI esteve negativamente associado a valores plasmáticos para receptor II de TNF- $\alpha$, IL6, sVCAM-1, sICAM-1 e insulina (34).

Com relação ao efeito do padrão da dieta mediterrânea sobre a inflamação crônica subclínica, uma maior adesão a ela vem sendo associada negativamente às concentrações de PCR, IL6, TNF- $\alpha$, fibrinogênio, homocisteína, sVCAM-1 e sICAM-1 (35-37). Além disso, o consumo de alguns alimentos que são considerados componentes da dieta mediterrânea também tem apresentado uma associação com menores concentrações de marcadores inflamatórios e de função endotelial (IL6, sVCAM-1, sICAM-1) (38). Nesse sentido, o aumento no consumo de azeite de oliva (15 versus $26,8 \mathrm{~g} / \mathrm{d}$ ), frutas, hortaliças e frutos secos (198 versus $487 \mathrm{~g} / \mathrm{d}$ ), por indivíduos com $\mathrm{SM}$, resultou em uma redução significativa nas concentrações plasmáticas de PCR, IL6, IL7 e IL18, entre outros marcadores (39).

Assim, os estudos epidemiológicos indicam que o efeito modulador de um padrão alimentar saudável (geralmente caracterizado por um alto consumo de frutas, hortaliças, carnes magras, grãos integrais e frutos secos) sobre as concentrações plasmáticas de adipocinas e outros biomarcadores inflamatórios e pró-aterogênicos poderia ser um dos mecanismos para a melhora das manifestações clínicas da SM e a redução da mortalidade.
Esse efeito benéfico pode estar associado a uma ação sinérgica dos nutrientes, ingredientes e alimentos que caracterizam tal padrão alimentar.

Entretanto, é importante destacar que o poder dos padrões alimentares, descritos anteriormente, de predizer a variação de marcadores de resistência insulínica, de inflamação e de aterogênese pode variar de acordo com os grupos de alimentos selecionados e o perfil lipídico apresentado. Neste sentido, quando avaliada a possível associação entre padrões alimentares, definidos pelos índices HEI, AHEI, DQI-R e aMED, e marcadores de inflamação e disfunção endotelial, as concentrações de marcadores investigados (PCR, IL6, seletina-E, sVCAM-1 e sICAM-1) foram somente associadas negativamente aos escores dos índices AHEI e aMED (10). Os autores justificam que ambos índices incluem o alto consumo de frutas e hortaliças, grãos integrais, frutos secos e peixe, bem como o consumo moderado de álcool. Além disso, AHEI inclui a razão entre ácidos graxos poli-insaturados e os saturados, enquanto o aMED inclui a razão entre ácidos graxos monoinsaturados e os saturados na pontuação de seus escores (10). Assim, a capacidade de especificar o perfil de ácidos graxos e de micronutrientes em um padrão alimentar pelo consumo de grupos de alimentos específicos pode aumentar a capacidade de avaliar o risco para doenças crônicas e biomarcadores associados à exposição à dieta habitual.

\section{EFEITO DE FATORES DIETÉTICOS ESPECÍFICOS SOBRE A REGULAÇÃO HORMONAL E DE BIOMARCADORES INFLAMATÓRIOS}

Se a avaliação do padrão alimentar é um bom instrumento para avaliar o efeito de uma dieta habitual como um todo, o estudo de mecanismos de ação de fatores dietéticos específicos, por sua vez, pode ser de grande relevância na prevenção de doenças crônicas, bem como no planejamento dietético para o tratamento da obesidade e de complicações associadas (Figura 1). De fato, o conteúdo calórico e o perfil de macronutrientes da dieta, seu perfil lipídico e o conteúdo de micronutrientes essenciais vêm sendo bastante discutidos com base em achados de estudos epidemiológicos e de ensaios clínicos (19,39-42).

\section{Perfil de ácidos graxos da dieta}

O consumo de ácidos graxos saturados (AGS) e de ácidos graxos trans (AGt) é considerado um importante fator de risco para as DCV em razão de seu efeito no 


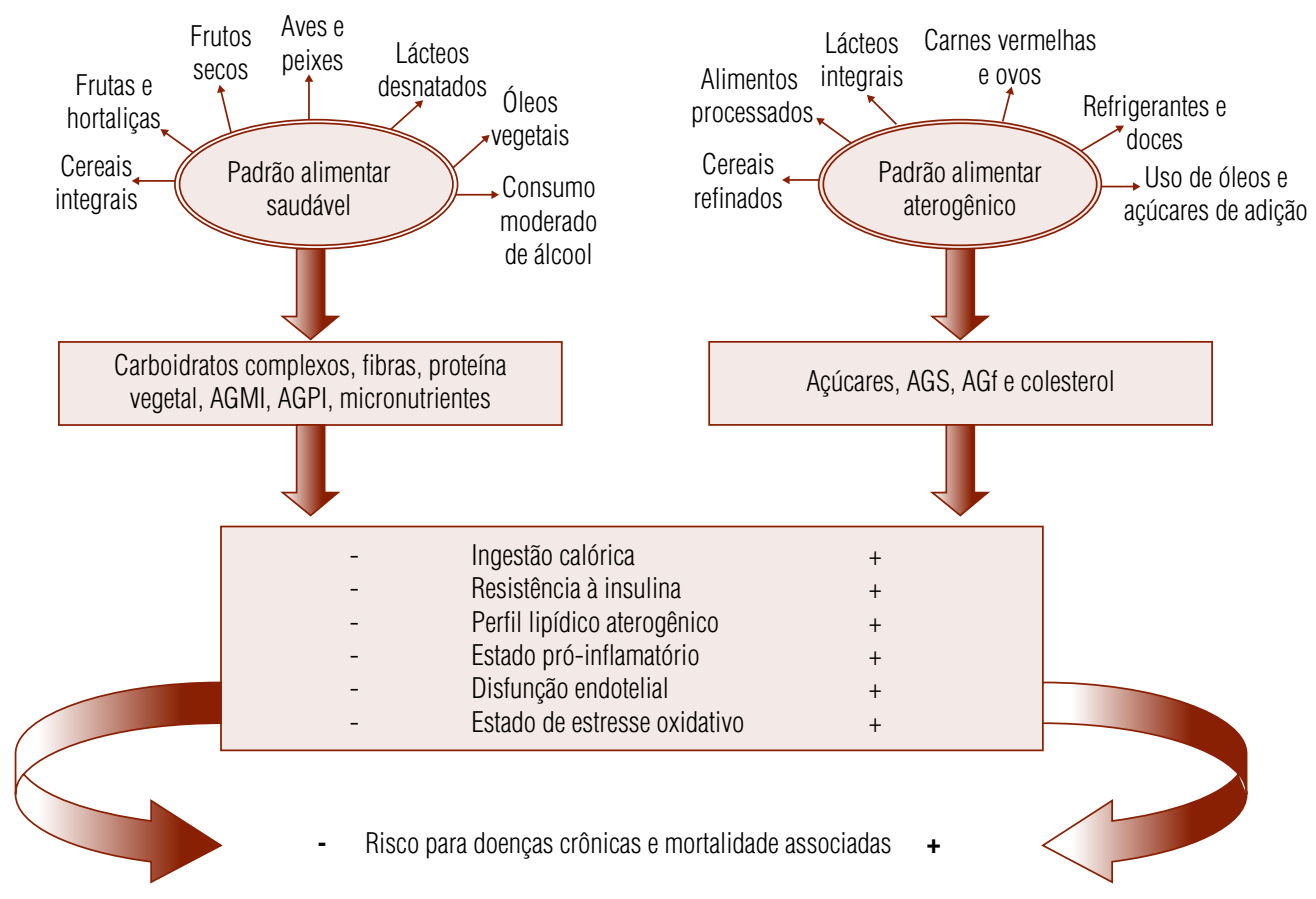

Figura 1. Efeitos potenciais da adoção de padrões alimentares considerados saudáveis e aterogênicos sobre o risco para doenças crônicas e associados à ingestão de fatores dietéticos específicos.

aumento das concentrações séricas de colesterol total e LDL-c e na redução de HDL-c, o que caracteriza um perfil lipídico aterogênico $(43,44)$. Além disso, o consumo de AGS proporciona uma menor liberação de proteínas relacionadas à saciedade, como a colecistocinina (CCK), o peptídeo tipo glucagon-1 (GLP-1) e o peptídeo tirosina-tirosina (PYY) (45), o que pode levar a uma maior ingestão calórica e um balanço energético positivo, uma das principais causas da obesidade.

Em modelos animais, o consumo de uma dieta rica em AGS estimula a secreção pancreática de insulina, bem como aumenta a expressão de RNAm de resistina e reduz a expressão de adiponectina e do receptor GLUT-4 em adipócitos, indicando o efeito potencial desses ácidos graxos no desenvolvimento da RI $(45,46)$. O consumo de uma dieta rica em AG $t$ também parece produzir um aumento na expressão da resistina e uma expressão reduzida do fator de transcrição ativado por ligantes (PPAR- $\gamma$ ), associado a uma menor sensibilidade à insulina (46). Com relação ao efeito desses ácidos graxos sobre os biomarcadores inflamatórios, os estudos epidemiológicos têm mostrado uma associação positiva entre a quantidade ingerida de AGS e as concentrações de PCR (47), bem como da ingestão de AGt com maio- res concentrações de biomarcadores inflamatórios como o TNF- $\alpha$, a IL6, a PCR (15), a sVCAM-1 e a sICAM-1 (48). A ingestão de $8 \%$ do valor calórico total (VCT) da dieta em AGt em comparação à mesma proporção em carboidrato ou ácido oleico produziu um aumento nas concentrações plasmáticas de PCR e seletina-E. Ainda, a ingestão de $8 \%$ do VCT em AGS (ácidos graxos láurico, mirístico e palmítico) resultou em um aumento nas concentrações de fibrinogênio e PCR em comparação a uma dieta rica em ácido oleico (49).

Os possíveis mecanismos de ação dos AGt na inflamação e função endotelial estão relacionados à sua incorporação nos fosfolipídeos das membranas celulares do endotélio vascular, monócitos, macrófagos e adipócitos, alterando a função dos receptores específicos destas células e das vias de sinalização e transcrição (43). Neste sentido, o consumo de AGS facilita um maior acúmulo de gordura corporal, ativa fatores de transcrição como o NF- $\kappa \beta$ e as proteínas quinases de mitogênio ativado no tecido adiposo e nas células de função imune, com consequente aumento na expressão de citocinas como ILl e TNF $\alpha$, diminui a expressão do coativador- 1 do PPAR- $\gamma$ e da adiponectina, produzindo menor oxidação de glicose e ácidos graxos, aumenta o recrutamento de 
macrófagos no tecido adiposo, todos mecanismos próinflamatórios e antagonistas à ação da insulina (50).

Entre os ácidos graxos monoinsaturados (AGMI), o ácido oleico é o principal representante e o azeite de oliva e alguns frutos secos são as duas fontes mais importantes desse ácido graxo na dieta. Diferentemente dos AGS e dos AGt, a ingestão de AGMI, por meio do consumo de azeite de oliva e frutos secos, não está relacionada ou é fator de proteção para o ganho de peso na população mediterrânea segundo os resultados do estudo de coorte Seguimiento Universidad de Navarra (SUN) $(51,52)$. De fato, a ingestão desses ácidos graxos estimula uma maior liberação do GLP-1 e do PYY quando comparada à ingestão de AGS e de carboidratos, relacionando-se, assim, a um melhor controle glicídico e maior poder de saciedade $(42,45)$. Da mesma maneira, a substituição dos AGS pelos AGMI tem um efeito benéfico sobre o perfil lipídico sérico com uma diminuição nos níveis de LDL-c e triglicérides e consequente ação preventiva perante a aterosclerose (53).

Com relação ao seu efeito sobre o estado inflamatório, estudos observacionais têm encontrado uma associação inversa entre o consumo de azeite de oliva e a expressão de TNF- $\alpha$ e sVCAM-1 (36), bem como com o risco de desenvolver aterosclerose (54). Em um estudo de intervenção nutricional, o consumo de dietas ricas em AGMI, tendo os frutos secos como principal fonte $(45$ a $60 \mathrm{~g})$, durante quatro semanas, produziu uma redução na expressão de SVCAM-l em pacientes hipercolesterolêmicos (17). Em outro estudo, o seguimento de uma dieta rica em ácido oleico ( $8 \%$ do VCT) e com uma ingestão de $38,9 \%$ do VCT em lipídeos levou a uma redução significativa das concentrações de IL6 comparada à ingestão de AGS (8\% do VCT) e mesma proporção total de lipídeos (49).

Por sua vez, entre os ácidos graxos poli-insaturados (AGPI), destacam-se os ácidos graxos $\omega$-3 ( $\alpha$-linolênico ALA, eicosapentanoico-EPA, docosa-hexaenoico-DHA) e os ácidos graxos $\omega-6$ (linoleico - LA), ambos nutrientes essenciais. Os ácidos EPA e DHA são predominantemente encontrados nos peixes e em seus óleos, enquanto o ALA, um precursor dos dois primeiros, tem como fonte alimentar os óleos de canola, soja e linhaça e as nozes.

Em recente metanálise incluindo 14 estudos clínicos aleatórios, 25 estudos prospectivos de coorte e 7 de casos-controle, a ingestão de $\omega$ - 3 por meio do consumo de peixes e óleos de peixe associou-se inversamente à mortalidade súbita ou por $\mathrm{DCV}(55)$. Além disso, eles podem influenciar outros aspectos da patogênese das
DCV como o perfil lipídico sérico, oxidação desses lipídeos, agregação plaquetária e arritmia (56).

Ao mesmo tempo, os ácidos graxos EPA e DHA reduzem a produção de prostaglandinas e leucotrienos pró-inflamatórios originados pelo ácido araquidônico, indicando sua relevância no estado inflamatório (16). Entretanto, os mecanismos biológicos anti-inflamatórios e antiaterogênicos não estão totalmente estabelecidos, de modo que a hipótese de que os $\omega$-3 são moduladores de outros biomarcadores inflamatórios e da disfunção endotelial associados à obesidade e à SM continua sendo investigada.

Neste contexto, o menor consumo de ALA se associou a maiores concentrações de PCR, enquanto a menor ingestão de EPA esteve associada a maiores concentrações de IL6 e a ingestão total de ácidos graxos $\omega$-3 esteve inversamente associada às concentrações de IL6, TNF- $\alpha$, ILl (57), PCR, sVCAM-1, sICAM-1 e seletina-E em uma amostra de adultos saudáveis (48). Além disso, as concentrações de PCR, SAA e IL6 reduziram em 38, 23,1 e em 10,5\% depois do consumo diário de $15 \mathrm{~mL}$ de óleo de linhaça (rico em ALA) durante três meses, mas as concentrações desses marcadores não se modificaram depois do consumo de $15 \mathrm{~mL}$ de óleo de girassol (rico em LA) em pacientes dislipidêmicos (16). Outro estudo com pacientes hipercolesterolêmicos encontrou melhor efeito anti-inflamatório depois do consumo de uma dieta rica em ALA (LA/ALA: 1,5/1) comparado ao de uma rica em LA (LA/ALA: 3,5/1) pela redução significativa das concentrações de PCR, sVCAM-1 e seletina-E (58).

Em resumo, os ácidos graxos oleico e $\omega-3$ possuem importante papel anti-inflamatório, devendo seu consumo ser considerado, dentro de uma porcentagem calórica recomendada para ingestão total de lipídeos, como uma estratégia dietética para o tratamento da obesidade e da SM e para a prevenção das DCV.

\section{Micronutrientes}

O consumo de frutas e hortaliças está inversamente associado ao ganho de peso, às manifestações clínicas da SM (59-61) e às concentrações de PCR (61). Ao mesmo tempo, o consumo regular de dietas enriquecidas com frutas e leguminosas tem resultado em menores concentrações de colesterol total, LDL-c oxidado, malondialdeído (MDA) e de PCR em comparação ao consumo de dietas pobres nestes alimentos, melhorando o estresse oxidativo e o pró-inflamatório, associados à obesidade $(40,62,63)$. 
As frutas e hortaliças são ricas em micronutrientes com importante papel antioxidante que podem participar dos mecanismos protetores desses alimentos e modular o estado inflamatório e oxidativo associados à obesidade. Por exemplo, elevadas concentrações de LDL-c oxidada e de triglicerídeos estão associadas à disfunção endotelial, ao processo inflamatório crônico subclínico e ao desenvolvimento da aterosclerose (3). Por outro lado, o consumo de micronutrientes com capacidade antioxidante poderia inibir vários processos pró-oxidativos e pró-aterogênicos na parede endotelial e prevenir a aterosclerose e suas manifestações clínicas (64).

Com relação à associação entre micronutrientes e o estado inflamatório, estudos observacionais indicam que a ingestão total de antioxidantes $(65)$ ou a ingestão das vitaminas do complexo B, C e E e do selênio (64) associa-se a menores concentrações de PCR. Igualmente, maiores concentrações plasmáticas das vitaminas $\mathrm{C}$, E e A e do selênio estão associadas a menores concentrações de PCR (66) e a um menor risco para SM (67).

Em um estudo de intervenção nutricional, indivíduos saudáveis que receberam uma dieta rica em lipídeos ( $59,2 \%$ do VCT) enriquecida com vitamina C (184 mg), $\mathrm{E}(19,5 \mathrm{mg}), \beta$-caroteno $(15 \mathrm{mg})$ e fibras $(9,6 \mathrm{~g})$ apresentaram uma menor resposta de agregação plaquetária, bem como menores concentrações de PAI-1, em comparação aos valores obtidos com o consumo de uma dieta rica em lipídeos sem suplementação (18). Outro estudo apresentou uma redução das concentrações de PAI-1 e seletina-P em indivíduos portadores de diabetes após a suplementação com $\alpha$-tocoferol (1200 UI) (68). Entretanto, a suplementação diária com as vitaminas C (250 mg) e $\alpha$-tocoferol (136 UI), durante três anos, não teve efeito nas concentrações de IL6, TNF $\alpha$ e PCR em indivíduos hipercolesterolêmicos (69); assim como a suplementação com vitaminas C (1000 mg) e $\alpha$-tocoferol (400 UI) em pacientes com doença coronária diagnosticada resultou na redução das concentrações de sICAM-1, mas não teve efeito nas concentrações de PCR, sVCAM-l e seletinas E e P, enquanto a mesma suplementação não apresentou nenhum efeito significante nas concentrações desses biomarcadores em indivíduos saudáveis (20).

Por sua vez, o selênio é um mineral essencial envolvido na proteção diante do dano causado pelo estresse oxidativo por ser um cofator de enzimas antioxidantes como a glutationa peroxidase e outras selenoproteínas. Assim, sua suplementação está associada a uma maior atividade enzimática, diminuição da peroxidação lipídica e menor risco para DCV (70). Além disso, o selênio parece ter relevante papel anti-inflamatório. Nesse sentido, a suplementação de selênio levou a uma diminuição na expressão de dois importantes genes pró-inflamatórios, ciclo-oxigenase-2 (COX-2) e TNF- $\alpha$, por meio da inibição de vias relacionadas às proteínas quinase de mitogênio ativado, sugerindo um efeito anti-inflamatório do selênio por meio da regulação de fatores de transcrição (71). Em estudos com humanos, o consumo de selênio da dieta foi inversamente associado à concentração plasmática da RBP4 (19) e do ácido siálico (72), enquanto a concentração de selênio em unhas foi inversamente relacionada à concentração do fator de complemento C3 (73), indicando também um papel anti-inflamatório potencial desse micronutriente. Por outra parte, o conteúdo de selênio nos alimentos é fortemente influenciado pela localização geográfica, períodos sazonais, conteúdo de proteína da dieta e procedimentos culinários. Além disso, sua biodisponibilidade varia de acordo com sua forma química (forma orgânica mais biodisponível: selênio-metionina diante do selênio sódico), bem como com o estado nutricional e hábito tabagista dos indivíduos estudados (74). Desse modo, apesar de os achados apresentados serem promissores, ainda são necessários mais estudos clínicos em longo prazo que confirmem o efeito desse micronutriente na prevenção de um estado inflamatório crônico subclínico e das DCV.

Com relação ao zinco, este tem importante papel na resposta imune, relacionando-se baixas concentrações de zinco à imunodeficiência, maior risco para infecções, além de maior risco para infarto do miocárdio e outras DCV $(75,76)$. O zinco também é cofator da enzima superóxido dismutase de ação antioxidante, além de ter relevante papel modulador sobre os leucócitos relacionados à expressão de citocinas, o que indica a sua participação no processo inflamatório (77).

Assim, a ingestão de vitaminas e minerais com propriedades antioxidantes parece ter um efeito adicional benéfico sobre o estresse oxidativo, o estado inflamatório e a função endotelial. Entretanto, mais estudos são necessários para que se avalie a magnitude desse efeito e os mecanismos implicados, de acordo com a dose oferecida (dentro ou acima das recomendações nutricionais), a biodisponibilidade de cada micronutriente e sua forma de consumo (em alimentos e/ou em suplementos). 


\section{CONSIDERAÇÕES FINAIS}

A utilização de índices para a avaliação de padrões alimentares de diferentes populações tem sido bastante útil para medir o risco para doenças crônicas em relação à exposição à dieta. Ao mesmo tempo, os padrões alimentares, caracterizados por tais índices, estão associados à variação de biomarcadores pró-inflamatórios e de disfunção endotelial em indivíduos, o que poderia explicar, em parte, o efeito da dieta habitual sobre o risco de incidência da SM e/ou das DCV. Entretanto, a capacidade de avaliar o efeito da dieta sobre o risco para doenças crônicas e biomarcadores associados pode variar de acordo com as características desses componentes, de modo que o estudo de fatores dietéticos específicos também se faz necessário.

Neste contexto, os ácidos graxos insaturados, especialmente o ácido oleico e o $\omega$-3, bem como os micronutrientes com capacidade antioxidante, podem ter um importante papel na prevenção e no tratamento da obesidade e comorbidades associadas quando incluídos em um padrão alimentar saudável. Entre os mecanismos de ação propostos, destaca-se a regulação hormonal com melhora na sensibilidade à insulina e liberação de hormônios relacionados à saciedade, bem como sua ação anti-inflamatória mediante a redução nas concentrações de citocinas, proteínas derivadas de hepatócitos e moléculas de adesão.

Agradecimentos: à Coordenação de Aperfeiçoamento de Nível Superior (Capes) pela bolsa de estudos e investigação de HHMH (Processo no 375605-0).

Declaração: os autores declaram não haver conflitos de interesse científico neste estudo.

\section{REFERÊNCIAS}

1. WHO. World Health Organization. Obesity: preventing and managing the global epidemic. Report of a WHO consultation. World Health Organ Tech Rep. 2000;894:1-253.

2. Rana JS, Nieuwdorp M, Jukema JW, Kastelein JJ. Cardiovascular metabolic syndrome - an interplay of obesity, inflammation, diabetes and coronary heart disease. Diabetes Obes Metab. 2007;9(3):218-32.

3. Van Gaal LF, Mertens IL, De Block CE. Mechanisms linking obesity with cardiovascular disease. Nature. 2006;444(7121):875-80.

4. Hermsdorff HH, Monteiro JB. Gordura visceral, subcutânea ou intramuscular: onde está o problema? Arq Bras Endocrinol Metabol. 2004;48(6):803-11.

5. Zulet MA, Puchau B, Navarro C, Martí A, Martínez JA. Biomarcadores del estado inflamatorio: nexo de unión con la obesidad y complicaciones asociadas. Nutr Hosp. 2007;22:511-27.

6. Volp AC, Alfenas Rde C, Costa NM, Minim VP, Stringueta PC, Bressan J. Capacidade dos biomarcadores inflamatórios em predizer a síndrome metabólica. Arq Bras Endocrinol Metabol. 2008;52(3):537-49.

7. Zulet MA, Puchau B, Navarro C, Marti A, Martinez JA. Biomarcadores del estado inflamatorio: nexo de unión con la obesidad y complicaciones asociadas. Nutr Hosp. 2007;22(5):511-27.

8. Hermsdorff HH, Volp ACP, Bressan J. Perfil de macronutrientes influencia a termogênese induzida pela dieta e a ingestão calórica. Arch Latinoam Nutr. 2007;57(1):33-42.

9. Martínez JA, Moreno MJ, Marques-Lopes I, Marti A. [Causes of obesity]. An Sist Sanit Navar. 2002;25 Suppl 1:17-27.

10. Fung TT, McCullough ML, Newby PK, Manson JE, Meigs JB, Rifai $\mathrm{N}$, et al. Diet-quality scores and plasma concentrations of markers of inflammation and endothelial dysfunction. Am J Clin Nutr. 2005;82(1):163-73.

11. Haines PS, Siega-Riz AM, Popkin BM. The Diet Quality Index revised: a measurement instrument for populations. J Am Diet Assoc. 1999;99(6):697-704.

12. McCullough ML, Feskanich D, Rimm EB, Giovannucci EL, Ascherio $A$, Variyam JN, et al. Adherence to the Dietary Guidelines for Americans and risk of major chronic disease in men. Am J Clin Nutr. 2000;72(5):1223-31.

13. Trichopoulou A, Costacou T, Bamia C, Trichopoulos D. Adherence to a Mediterranean diet and survival in a Greek population. N Engl J Med. 2003;348(26):2599-608.

14. Trichopoulou A, Kouris-Blazos A, Wahlqvist ML, Gnardellis C, Lagiou $P$, Polychronopoulos $E$, et al. Diet and overall survival in elderly people. BMJ. 1995;311(7018):1457-60.

15. Mozaffarian D, Pischon T, Hankinson SE, Rifai N, Joshipura K, Willett WC, et al. Dietary intake of trans fatty acids and systemic inflammation in women. Am J Clin Nutr. 2004;79(4):606-12.

16. Rallidis LS, Paschos G, Liakos GK, Velissaridou AH, Anastasiadis G, Zampelas A. Dietary alpha-linolenic acid decreases C-reactive protein, serum amyloid $A$ and interleukin- 6 in dyslipidaemic patients. Atherosclerosis. 2003;167(2):237-42.

17. Ros E, Nunez I, Perez-Heras A, Serra M, Gilabert R, Casals E, et al. A walnut diet improves endothelial function in hypercholesterolemic subjects: a randomized crossover trial. Circulation. 2004;109(13):1609-14.

18. Esposito K, Nappo F, Giugliano F, Giugliano G, Marfella R, Giugliano D. Effect of dietary antioxidants on postprandial endothelial dysfunction induced by a high-fat meal in healthy subjects. Am J Clin Nutr. 2003;77(1):139-43.

19. Hermsdorff HH, Zulet MA, Puchau B, Bressan J, Martinez JA. Association of retinol-binding protein-4 with dietary selenium intake and other lifestyle features in young healthy women. Nutrition. 2009;25(4):392-9.

20. Tahir M, Foley B, Pate G, Crean P, Moore D, McCarroll N, et al. Impact of vitamin $E$ and $C$ supplementation on serum adhesion molecules in chronic degenerative aortic stenosis: a randomized controlled trial. Am Heart J. 2005;150(2):302-6.

21. Nettleton JA, Schulze MB, Jiang R, Jenny NS, Burke GL, Jacobs DR Jr. A priori-defined dietary patterns and markers of cardiovascular disease risk in the Multi-Ethnic Study of Atherosclerosis (MESA). Am J Clin Nutr. 2008;88(1):185-94.

22. Trichopoulou A, Orfanos $P$, Norat T, Bueno-de-Mesquita B, Ocke $\mathrm{MC}$, Peeters $\mathrm{PH}$, et al. Modified Mediterranean diet and survival: EPIC-elderly prospective cohort study. BMJ. 2005;330(7498):991.

23. Hu FB. Dietary pattern analysis: a new direction in nutritional epidemiology. Curr Opin Lipidol. 2002;13(1):3-9.

24. Kant AK. Dietary patterns and health outcomes. J Am Diet Assoc. 2004;104(4):615-35.

25. Kennedy E, Ohls J, Carlon S, Fleming K. The healthy eating index final report. Alexandria: Food and Nutrition Service, US Department of Agriculture; 1994. 
26. Kant AK, Schatzkin A, Graubard BI, Schairer C. A prospective study of diet quality and mortality in women. JAMA. 2000;283(16):2109-15.

27. Patterson RE, Haines PS, Popkin BM. Diet quality index: capturing a multidimensional behavior. J Am Diet Assoc. 1994;94(1):57-64.

28. McCullough ML, Feskanich D, Stampfer MJ, Giovannucci EL, Rimm EB, Hu FB, et al. Diet quality and major chronic disease risk in men and women: moving toward improved dietary guidance. Am J Clin Nutr. 2002;76(6):1261-71.

29. Esmaillzadeh A, Kimiagar M, MehrabiY, Azadbakht L, Hu FB, Willett WC. Dietary patterns and markers of systemic inflammation among Iranian women. J Nutr. 2007;137(4):992-8.

30. Babio N, Bullo M, Basora J, Martinez-Gonzalez MA, FernandezBallart J, Marquez-Sandoval F, et al. Adherence to the Mediterranean diet and risk of metabolic syndrome and its components. Nutr Metab Cardiovasc Dis. 2009. [Epub ahead of print]

31. Martínez-González MA, de la Fuente-Arrillaga $C$, Nuñez-Cordoba JM, Basterra-Gortari FJ, Beunza JJ, Vazquez Z, et al. Adherence to Mediterranean diet and risk of developing diabetes: prospective cohort study. BMJ. 2008;336(7657):1348-51.

32. Boynton A, Neuhouser ML, Wener MH, Wood B, Sorensen B, Chen-Levy $Z$, et al. Associations between healthy eating patterns and immune function or inflammation in overweight or obese postmenopausal women. Am J Clin Nutr. 2007;86(5):1445-55.

33. Nanri A, Yoshida D, Yamaji T, Mizoue T, Takayanagi R, Kono S. Dietary patterns and C-reactive protein in Japanese men and women. Am J Clin Nutr. 2008;87(5):1488-96.

34. Fargnoli JL, Fung TT, Olenczuk DM, Chamberland JP, Hu FB, Mantzoros CS. Adherence to healthy eating patterns is associated with higher circulating total and high-molecular-weight adiponectin and lower resistin concentrations in women from the Nurses' Health Study. Am J Clin Nutr. 2008;88(5):1213-24.

35. Chrysohoou C, Panagiotakos DB, Pitsavos C, Das UN, Stefanadis C. Adherence to the Mediterranean diet attenuates inflammation and coagulation process in healthy adults: the ATTICA Study. $J$ Am Coll Cardiol. 2004;44(1):152-8.

36. Serrano-Martínez M, Palacios M, Martinez-Losa E, Lezaun R, Maravi $C$, Prado $M$, et al. A Mediterranean dietary style influences TNF-alpha and VCAM-1 coronary blood levels in unstable angina patients. Eur J Nutr. 2005;44(6):348-54.

37. Dai J, Miller AH, Bremner JD, Goldberg J, Jones L, Shallenberger $\mathrm{L}$, et al. Adherence to the Mediterranean diet is inversely associated with circulating interleukin- 6 among middle-aged men: a twin study. Circulation. 2008;117(2):169-75.

38. Salas-Salvadó J, Garcia-Arellano A, Estruch R, Marquez-Sandoval F, Corella D, Fiol M, et al. Components of the Mediterranean-type food pattern and serum inflammatory markers among patients at high risk for cardiovascular disease. Eur J Clin Nutr. 2008;62(5):651-9.

39. Esposito K, Marfella R, Ciotola M, Di Palo C, Giugliano F, Giugliano $G$, et al. Effect of a Mediterranean-style diet on endothelial dysfunction and markers of vascular inflammation in the metabolic syndrome: a randomized trial. JAMA. 2004;292(12):1440-6.

40. Crujeiras $A B$, Parra MD, Rodriguez MC, Martínez de Morentin $\mathrm{BE}$, Martínez JA. A role for fruit content in energy-restricted diets in improving antioxidant status in obese women during weight loss. Nutrition. 2006;22(6):593-9.

41. Hermsdorff HHM, Zulet MA, Bressan J, Martínez JA. Efecto de la restricción calórica y del perfil de los macronutrientes sobre las citoquinas como biomarcadores de inflamación. Rev Esp Obes. 2008;6(1):9-20.

42. Paniagua JA, de la Sacristana AG, Sanchez E, Romero I, VidalPuig A, Berral FJ, et al. A MUFA-rich diet improves posprandial glucose, lipid and GLP-1 responses in insulin-resistant subjects. J Am Coll Nutr. 2007;26(5):434-44.
43. Mozaffarian D. Trans fatty acids - effects on systemic inflammation and endothelial function. Atheroscler Suppl. 2006;7(2):29-32.

44. Sundram K, French MA, Clandinin MT. Exchanging partially hydrogenated fat for palmitic acid in the diet increases LDL-cholesterol and endogenous cholesterol synthesis in normocholesterolemic women. Eur J Nutr. 2003;42(4):188-94.

45. Karhunen LJ, Juvonen KR, Huotari A, Purhonen AK, Herzig KH. Effect of protein, fat, carbohydrate and fibre on gastrointestinal peptide release in humans. Regul Pept. 2008;149(1-3):70-8.

46. Saravanan N, Haseeb A, Ehtesham NZ, Ghafoorunissa. Differential effects of dietary saturated and trans-fatty acids on expression of genes associated with insulin sensitivity in rat adipose tissue. Eur J Endocrinol. 2005;153(1):159-65.

47. Arya S, Isharwal S, Misra A, Pandey RM, Rastogi K, Vikram NK, et al. C-reactive protein and dietary nutrients in urban Asian Indian adolescents and young adults. Nutrition. 2006;22(9):865-71.

48. López-Garcia E, Schulze MB, Manson JE, Meigs JB, Albert CM, Rifai $N$, et al. Consumption of (n-3) fatty acids is related to plasma biomarkers of inflammation and endothelial activation in women. J Nutr. 2004;134(7):1806-11.

49. Baer DJ, Judd JT, Clevidence BA, Tracy RP. Dietary fatty acids affect plasma markers of inflammation in healthy men fed controlled diets: a randomized crossover study. Am J Clin Nutr. 2004;79(6):969-73.

50. Kennedy A, Martinez K, Chuang CC, LaPoint K, Mclntosh M. Saturated fatty acid-mediated inflammation and insulin resistance in adipose tissue: mechanisms of action and implications. J Nutr. 2009;139(1):1-4.

51. Bes-Rastrollo M, Sabate J, Gómez-Gracia E, Alonso A, Martínez JA, Martínez-González MA. Nut consumption and weight gain in a Mediterranean cohort:The SUN study. Obesity (Silver Spring). 2007;15(1):107-16.

52. Bes-Rastrollo M, Sanchez-Villegas $A$, de la Fuente $C$, de Irala J, Martinez JA, Martinez-Gonzalez MA. Olive oil consumption and weight change: the SUN prospective cohort study. Lipids. 2006;41(3):249-56.

53. Martínez-González MA, Bes-Rastrollo M. The cardioprotective benefits of monounsaturated fatty acid. Altern Ther Health Med. 2006;12(1):24-30.

54. Buil-Cosiales P, Irimia P, Berrade N, Garcia-Arellano A, Riverol M, Murie-Fernandez $M$, et al. Carotid intima-media thickness is inversely associated with olive oil consumption. Atherosclerosis. 2008;196(2):742-8.

55. Wang $C$, Harris WS, Chung M, Lichtenstein AH, Balk EM, Kupelnick $B$, et al. n-3 Fatty acids from fish or fish-oil supplements, but not alpha-linolenic acid, benefit cardiovascular disease outcomes in primary- and secondary-prevention studies: a systematic review. Am J Clin Nutr. 2006;84(1):5-17.

56. Brown AA, Hu FB. Dietary modulation of endothelial function: implications for cardiovascular disease. Am J Clin Nutr. 2001;73(4):673-86.

57. Ferrucci L, Cherubini A, Bandinelli S, Bartali B, Corsi A, Lauretani F, et al. Relationship of plasma polyunsaturated fatty acids to circulating inflammatory markers. J Clin Endocrinol Metab. 2006;91(2):439-46.

58. Zhao G, EthertonTD, Martin KR, West SG, Gillies PJ, Kris-Etherton PM. Dietary alpha-linolenic acid reduces inflammatory and lipid cardiovascular risk factors in hypercholesterolemic men and women. J Nutr. 2004;134(11):2991-7.

59. Alonso A, Beunza JJ, Bes-Rastrollo M, Pajares RM, Martínez-González MA. Vegetable protein and fiber from cereal are inversely associated with the risk of hypertension in a Spanish cohort. Arch Med Res. 2006;37(6):778-86.

60. Bes-Rastrollo M, Martínez-González MA, Sánchez-Villegas A, de la Fuente Arrillaga $C$, Martínez JA. Association of fiber intake and fruit/vegetable consumption with weight gain in a Mediterranean population. Nutrition. 2006;22(5):504-11. 
61. Esmaillzadeh A, Kimiagar M, MehrabiY, Azadbakht L, Hu FB, Willett WC. Fruit and vegetable intakes, $\mathrm{C}$-reactive protein, and the metabolic syndrome. Am J Clin Nutr. 2006;84(6):1489-97.

62. Crujeiras AB, Parra D, Abete I, Martínez JA. A hypocaloric diet enriched in legumes specifically mitigates lipid peroxidation in obese subjects. Free Radic Res. 2007;41(4):498-506.

63. Watzl B, Kulling SE, Moseneder J, Barth SW, Bub A. A 4-wk intervention with high intake of carotenoid-rich vegetables and fruit reduces plasma $\mathrm{C}$-reactive protein in healthy, nonsmoking men. Am J Clin Nutr. 2005;82(5):1052-8.

64. Scheurig AC, Thorand B, Fischer B, Heier M, Koenig W. Association between the intake of vitamins and trace elements from supplements and C-reactive protein: results of the MONICA/KORA Augsburg study. Eur J Clin Nutr. 2008;62(1):127-37.

65. Brighenti F, Valtuena S, Pellegrini N, Ardigo D, Del Rio D, Salvatore $\mathrm{S}$, et al. Total antioxidant capacity of the diet is inversely and independently related to plasma concentration of high-sensitivity C-reactive protein in adult Italian subjects. Br J Nutr. 2005;93(5):619-25.

66. van Herpen-Broekmans WM, Klopping-Ketelaars IA, Bots ML, Kluft C, Princen $\mathrm{H}$, Hendriks HF, et al. Serum carotenoids and vitamins in relation to markers of endothelial function and inflammation. Eur J Epidemiol. 2004;19(10):915-21.

67. Ford ES, Mokdad AH, Giles WH, Brown DW. The metabolic syndrome and antioxidant concentrations: findings from the Third National Health and Nutrition Examination Survey. Diabetes. 2003;52(9):2346-52.

68. Devaraj S, Chan AV Jr., Jialal I. alpha-Tocopherol supplementation decreases plasminogen activator inhibitor-1 and P-selectin levels in type 2 diabetic patients. Diabetes Care. 2002;25(3):524-9.
69. Bruunsgaard H, Poulsen HE, Pedersen BK, Nyyssonen K, Kaikkonen J, Salonen JT. Long-term combined supplementations with alpha-tocopherol and vitamin $C$ have no detectable anti-inflammatory effects in healthy men. J Nutr. 2003;133(4):1170-3.

70. Rayman MP. The importance of selenium to human health. Lancet. 2000;356(9225):233-41.

71. Vunta H, Belda BJ, Arner RJ, Channa Reddy C, Vanden Heuvel JP, Sandeep Prabhu K. Selenium attenuates pro-inflammatory gene expression in macrophages. Mol Nutr Food Res. 2008.

72. Zulet MA, Puchau B, Hermsdorff HH, Navarro C, Martinez JA. Dietary selenium intake is negatively associated with serum sialic acid and metabolic syndrome features in healthy young adults. Nutr Res. 2009;29(1):41-8.

73. Puchau B, Zulet MA, Gonzalez de Echavarri A, Navarro-Blasco I, Martinez JA. Selenium intake reduces serum $\mathrm{C}_{3}$, an early marker of metabolic syndrome manifestations, in healthy young adults. Eur J Clin Nutr. 2008:1-7.

74. Rayman MP. Food-chain selenium and human health: emphasis on intake. Br J Nutr. 2008;100(2):254-68.

75. Elcarte LopezT, Villa Elizaga I, Gost Garde JI, Elcarte Lopez R, Martin Perez A, Navascues Pujada J, et al. Cardiovascular risk factors in relation to the serum concentrations of copper and zinc: epidemiological study on children and adolescents in the Spanish province of Navarra. Acta Paediatr. 1997;86(3):248-53.

76. Martin-Moreno JM, Gorgojo L, Riemersma RA, Gomez-Aracena $\mathrm{J}$, Kark JD, Guillen J, et al. Myocardial infarction risk in relation to zinc concentration in toenails. Br J Nutr. 2003;89(5):673-8.

77. Kontogianni MD, Zampelas A, Tsigos $C$. Nutrition and inflammatory load. Ann NY Acad Sci. 2006;1083:214-38. 